\title{
Indios(as), Nación y (ausencia de) Reconocimiento ${ }^{1}$
}

\section{Indigenous people, Nation and (lack of) Recognition}

\author{
Elsa Gabriela González Caniulef \\ gabgonza@gmail.com
}

\begin{abstract}
SÍNTESIS
Este ensayo proporciona algunos ejes centrales desde donde la teoría del reconocimiento aporta nuevas herramientas de análisis social para los estudios de género y raza/etnicidad. El texto abarca una revisión bibliográfica que abre interrogantes conectadas a la construcción de identidades étnicas y de nación, a la búsqueda de reconocimiento por parte de sujetos indígenas, y otros nichos discursivos que se han vuelto contingentes.
\end{abstract}

\begin{abstract}
This work explores how the theory of recognition contributes new social analysis tools to the studies of gender/ethnicity. The text covers a bibliographic revision which opens question marks linked to the identity and nation construction, the seeking for recognition by the indigenous subjects, and other contingent discursive resources.
\end{abstract}

Palabras claves: identidad, reificación, raza/etnicidad, género.

Keywords: identity, reification, race/ethnicity, gender studies.

Existe una importante contribución teórica para un enfoque relacional entre el género y la raza que fuera realizada en un conocido texto de los estudios de género. Se trata de la siguiente pregunta: “Qué es un esclavo negro?”; que se responde como sigue: “Un hombre de raza negra. Solo se convierte en esclavo en determinadas relaciones" (Rubin, 1986: 96), destacando, así, la intrincada relación que adquiere la coyuntura raza/género en contextos de dominación. La fuerza de esta aseveración parece adquirir importancia a la vista de hechos contingentes que dicen relación con el lejano horizonte 
para alcanzar efectivas relaciones interculturales en Chile. Y es que haciendo una analogía en torno al poder/saber simbólico que opera en procesos de conquista y colonialismo cabe recordar, por ejemplo, que hombres y mujeres mapuche pasaron a ser indios/as, con toda la connotación peyorativa que involucra el término sólo a partir de contextos de relación/contacto con otros ${ }^{2}$. Dicho de otra forma, el epíteto que catapultó a los mapuche y otros pueblos originarios de América Latina como indios solo fue posible en un contexto de fallido contacto intercultural que adoleció de falta de reconocimiento, entre españoles e indígenas durante el periodo colonial y entre criollos e indígenas en el período de formación y consolidación de la república. Este único antecedente, se constituye, en sí mismo, como un poderoso motor para seguir realizando revisiones sociohistóricas sobre el tema a fin de indagar las posibilidades existentes para poder construir relaciones intersubjetivas desprovistas de doxas que perpetúan cierto tipo de ideología, cierto tipo de prácticas y, por consecuencia, cierto tipo de inclusión/exclusión social en función de marcas étnico-raciales y/o de género. En tal sentido, la paradoja expresada por Verena Stolcke en relación a que aun cuando "Las 'razas' no existen como fenómenos naturales, mientras que la etnicidad, a pesar de las buenas intenciones, tiende a ser concebida como característica de grupo no puramente cultural, siendo naturalizada" (2000: 41) es clave para entender que tanto la raza como la etnicidad, entonces, son "construcciones simbólicas" (2000: 41) que, sin embargo, naturalizan rasgos culturales o criterios biológicos (Stolcke 3941.) .

\section{Construcción de nación y ausencia de sujeto indígena en Chile}

$\mathrm{Al}$ revisar el pasado republicano chileno, cuando se revisan algunas fuentes escritas legadas desde el siglo XIX buscando pistas sobre los pueblos indígenas, inevitablemente, se asiste a una escena: la del debate respecto al grado de civilización de éstos y el lugar que, en tal sentido, les correspondía en lo que en la época se consideraba como admisiblemente humano y, consecuentemente, en el proyecto de nación. Para los pueblos indígenas en general y, en particular, para el pueblo mapuche la taxonomía social no fue favorable. Puestas así las cosas, entonces, se comprende el abreviado espacio que ocupa este pueblo, por ejemplo, en la historiografía. Un hecho que devela 
como en Chile el discurso ${ }^{3}$ que primó en el proceso de construcción de la nación y el tipo de ubicación que les correspondía a los sujetos indígenas en tal proyecto fue de tipo excluyente, toda vez que se superpuso una idea: la de homogeneidad racial y cultural (Casanova, 1999; Gallardo, 2000; Pinto, 2003). Así, no resulta extraño que en nuevas lecturas de la historia nacional se exprese que el discurso de la exclusión que se hizo manifiesto -y que se torna homologable a las prácticas en relación a la diversidad cultural de otros países de la región ${ }^{4}$ - se hizo patente en la omisión y degradación de los(as) mapuche en el relato histórico, entre otros.

El camino que consolidó este Programa se vio favorecido por varios factores notoriamente visibles en lo que fue el proceso de construcción de la nación. En el ámbito de la difusión de ideas la concreción de éstas tuvo lugar en las opiniones vertidas a través de periódicos, discursos políticos, promulgación de leyes, en agrupaciones sociales, así como en la propagación del ideario en la instrucción pública ${ }^{5}$, entre otros (Subercaseaux en Loyola y Grez: 166); en el ámbito de una praxis de inteligencia social enfocada a la dominación, se mantuvo la estructura de infiltramiento heredada del período colonial $^{6}$ a la que se sumó la presencia de exploradores expertos o surveys $^{7}$ quienes en nombre de la ciencia no solo dieron cuenta detallada de recursos naturales, sino además, prácticamente, inventariaron habitantes, armas defensivas y rutas de acceso existentes en los territorios considerados enemigos. Según la historia mapuche, escrita recientemente a contracorriente, las distintas estrategias descritas tuvieron como punto de culminación la conquista del Wallma$p u^{8}$ (Marimán et al, 2006).

En el largo proceso histórico-social que tuvo lugar en forma previa a este acontecimiento -y que converge con la consolidación del proyecto de nación en Chile- se desencadenaron numerosos hechos entre los que destaca uno en particular: me refiero a que, desde el momento del contacto entre los mapuche con grupos humanos exógenos a sus territorios, discursos atingentes a raza comenzaron a permear los imaginarios sociales entre la población que actuó como (neo)colonizadora y que comenzó a detentar el poder representante de la civilización 9 . Mecanismos de este tipo y/o de segregación según condición de género escasamente son mencionados, en tanto procesos histórico-ideológicos, en investigaciones que abordan los 
procesos de construcción de nación y los efectos derivados de situaciones de violencia o conflictos, que desencadenan formas de subordinación o dominación. Desde esta perspectiva, una primera idea es considerar los conflictos interétnicos y/o interraciales como fenómenos susceptibles de activar mecanismos de construcción/captación de alteridad cuyas huellas es posible encontrar en las formaciones discursivas (y simbólicas) para referir a la otredad ${ }^{10}$.

Esta idea se enlaza con indagaciones referidas a los factores que intervienen en prácticas de desigualdad en función del género, en tanto ha quedado consignado que "las diferencias sociales y de género están enraizadas en los "hechos" biológicos de la raza y el sexo" (Stolcke, 1992: 80) o que "La continua utilización del pensamiento biosocial y el recurso a la naturalización de las categorías sociales representa un mecanismo clave en el funcionamiento del racismo y del sexismo en la sociedad" (Nash, 2003: s/p); aludiendo, así, al modo en que ciertos discursos planteados desde la hegemonía, cuando son amparados en argumentos científicos (para otorgar mayor credibilidad), se tornan en poderosos determinantes en la generación de condiciones simbólicas y materiales adversas para aquellos(as) sobre quienes pesa el atributo biológico/cultural que no favorece.

Para el caso chileno, fue en el espacio del discurso donde el vigor del significante, unido a otras condiciones e intereses, inclinó arbitrariamente la balanza a favor del grupo que según la doxa del diferenciado origen racial se consideró a sí mismo como superior y con la investidura de poder que posibilitaba matar, ultrajar y despojar de sus territorios a quienes consideró inferiores. Para autores como Peter Wade, por ejemplo, "la noción de que las razas sea una construcción social no significa que carece de importancia (como si fueran 'meramente' ideas) (...) Si la gente discrimina en base a sus ideas raciales, se trata de una realidad social de enorme importancia" (Wade, 2000: 21) ${ }^{11}$. En específico, la propuesta de Wade apunta a continuar manteniendo la distinción basada en el enfoque atingente a raza (y, por supuesto, etnicidad) dado su carácter historicista y porque a pesar de los intentos por desmantelar el uso de este concepto, en los hechos continúa vigente; siendo, a nivel subjetivo, semánticamente homologable al concepto etnicidad ${ }^{12}$. Así, la categoría analítica en clave raza adquiere potencia al recordar que diversas historias de pueblos indígenas también han sido historias de (des) 
encuentro racial. Tras esto ¿es posible comprender la relación de violencia chileno/mapuche omitiendo este antecedente?

Huellas y reminiscencias del discurso racial -resignificado en la actualidad $^{13}$ - se rastrean prestando atención al habla o la escritura actual de no pocos(as) teóricos(as) sociales, políticos, funcionarios públicos, estudiantes, blogueros y twitteros de redes sociales, entre muchos locus provenientes de la sociedad mayor; quienes aún hoy tienen dificultad para comprender el, a ratos, inasible universo pluricultural indígena que les rodea. De ahí, entonces, que cuando se buscan explicaciones a las persistentes movilizaciones y demandas mapuche, y el escaso nivel de diálogo demostrado por el Estado chileno ${ }^{14}$, cobre sentido reactualizar el debate sobre la construcción de imaginarios sociales que portan creencias amparadas en la ideología racialista. En el contexto actual, acontece un desencuentro presente en las mentalidades y que se performativiza ${ }^{15}$ en los discursos etnocéntricos de la chilenidad ${ }^{16}$, posibilitando la emergencia de una especie de ciudadanía de segunda categoría para los descendientes/ sobrevivientes de estos pueblos.

En efecto, los discursos tienen múltiples formas de expresión en el ámbito social y a través de ellos se pueden observar como distintos campos de fuerza compiten, traslapan o influyen entre sí a fin de instaurar verdades. En este sentido y, específicamente, desde el modelo analítico concerniente al funcionamiento simbólico de las dicotomías conceptuales, que se activan en el lenguaje, se ha llegado a establecer que un "término primario o dominante deriva su privilegio de una supresión o limitación de su opuesto" (Gross en Scott, 1992: 90); de éste modo aquellos conceptos o términos que gozan de mayor prestigio se instalarán en una posición de mayor legitimidad mientras su opuesto será una "variante baja o impura, del concepto primario" (Gross en Scott, 1992: 90). En el contexto chileno esta pugna se refleja en los binarismos masculino/femenino o raza no amerindia versus raza indígena o afrodescendiente, donde salta a la vista cual ha sido la variante baja e impura.

Este tipo de (des)legitimación en el lenguaje y su posterior afiatamiento en el inconsciente colectivo ha tenido múltiples interpretaciones, sin embargo, interesa develar la arbitrariedad que entraña su propia elaboración. La construcción de imaginarios, que entiendo como la forma en que los discursos adquieren forma con el fin de lle- 
gar a instaurarse como verdades consideradas legítimas, cobra vigor cuando, por ejemplo, un grupo establecido en el poder se atribuye importantes intereses políticos, económicos o ideológicos que defender para preservar su posición privilegiada. Este hecho se advierte en el período de construcción de la nación en Chile, toda vez que siendo un proceso de confrontación ideológica, política, social, el debate que tomó lugar respecto de los sujetos mapuche se vio supeditado al sistema ideológico que resultó acomodaticio a los grupos de poder de la época ${ }^{17}$.

El sentido que atribuyen los sujetos a las identidades no es cuestión de azar ni es un hecho espontáneo, que surja de la nada; las identidades étnico/raciales y de género han sido terrenos simbólicos donde, por una parte, se pueden tipificar y moldear sujetos desde discursos hegemónicos $\mathrm{y}$, por otra parte, pueden ser un nicho que porta las huellas de un reconocimiento fallido cuando las condiciones societales han distado de ser favorables para algunos(as) de ellos(as). Así las cosas: "Los términos que nos permiten ser reconocidos como humanos son articulados socialmente y son variables. Y, en ocasiones, los mismos términos que confieren la cualidad de 'humano' a ciertos individuos son aquellos que privan a otros de la posibilidad de conseguir dicho estatus, produciendo así un diferencial entre lo humano y lo menos que humano" (Butler, 2006: 14). Intentar subestimar la relevancia que pueden tener hechos objetivos $-\mathrm{y}$ tan subjetivos a la vez- como éste en los procesos de construcción y representación de identidades sería pernicioso no solo por el intento de negación en sí mismo sino porque estos imaginarios no son solo hechos del pasado.

Slavoj Zizek en su análisis del funcionamiento de la ideología ha señalado la primacía de un tipo de razón cínica en la sociedad. Esta "no es ingenua, sino que es una paradoja de una falsa conciencia ilustrada: uno sabe de sobra la falsedad, está muy al tanto de que hay un interés particular oculto tras una universalidad ideológica, pero aun así, u cuando los individuos saben bien la realidad detrás de la relación entre las cosas tienden a actuar como fetichistas ${ }^{18}$. En términos específicos señala "ellos saben que, en su actividad, siguen una ilusión, pero aun así, lo hacen" ${ }^{19}$ (Zizek, 2003: 61.). El análisis de cómo operaría un mecanismo social de este tipo en términos simbólicos y en las propias prácticas de los sujetos -al extremo de que la propia creencia que moviliza un tipo de praxis se asume como un 
hecho natural, como un fenómeno de aparente normalidad- conduce a la revisión del concepto de reificación y, consecuentemente, a las investigaciones vinculadas a la teoría del reconocimiento.

\section{La búsqueda del reconocimiento.... ¿de qué modo?}

Durante las últimas décadas Axel Honneth ha introducido en la teoría crítica una reinterpretación de la reificación -en tanto posturas o actitudes que pueden llegar a tener los sujetos respecto de si mismos, como respecto de otros o el entorno ${ }^{20}$ - de acuerdo a la cual el punto cínico que da cuenta Zizek sería, por una parte, el olvido del reconocimiento. Por otra parte, las actitudes reificantes propiamente tales corresponderían a "prácticas o mecanismos que perpetúan sistemáticamente tal olvido" (Honneth, 2007: 136). Ejemplos icónicos que ilustran concretamente este tipo de prácticas se encuentran, por ejemplo, en los trabajos de Michel Foucault, Edward Said, quienes, entre otros, han develado el impacto de los imaginarios construidos a partir de la diferencia y las diversas formas de disciplinamiento que a partir de ahí intervienen en lo que se asume como un modelo socialmente válido.

Aunque el trabajo de Honneth no refiere como las conductas reificantes permean las relaciones interraciales, de género y/o de etnicidad, el marco de análisis y la reactualización del concepto que propone es lúcido al interpretar el funcionamiento de la ideología al señalar que las personas pueden adoptar una conducta reificante respecto de otras, o respecto de su entorno (las cosas), cuando:

han perdido de vista el reconocimiento previo de éstas por una de las dos causas siguientes: porque participan en una praxis social en la que la mera observación del otro se ha convertido en un fin en si mismo tal que toda la conciencia de una relación previa se extingue, o porque permiten que sus actos sean gobernados por un sistema de convicciones que impone una negación posterior de este reconocimiento original (Honneth, 2007: 137).

Desde esta perspectiva el alcance teórico de la reificación posibilita una vía de explicación a las formas que adquiere el modus operandi de las formas de regulación/dominación en función del género, la raza/ etnia $y$, más aún, se presta para cuestionar el modelo de aproximación científica o hermenéutica que posee cierto tipo de producción 
intelectual referido a pueblos indígenas ${ }^{21}$. Asimismo, la inflexión que convoca Honneth convoca una dimensión ética tácita que se muestra ausente al revisar las relaciones histórico-sociales de gran parte de las sociedades latinoamericanas modernas respecto de los pueblos originarios y afrodescendientes. Señalo lo anterior, toda vez que cuando Honneth recurre al lenguaje teórico del reconocimiento apunta a la necesaria implicación (con otros) como "expresión de la valoración del significado cualitativo que poseen otras personas o cosas para la ejecución de nuestra existencia" (Honneth, 2007: 56). En América Latina y Chile en particular se prescindió y obliteró la presencia de todos los grupos humanos que encarnaran la alteridad, anteponiéndose el mecanismo inverso, es decir la reificación de los sujetos indígenas ${ }^{22}$.

Una línea de argumentación que refleja similares preocupaciones -aunque con puntos divergentes en sus enfoques- también se encuentra en Nancy Fraser quien, al dar cuenta de expresiones de desigualdad (en el ámbito económico), señala que las personas se pueden ver impedidas de participar con los demás como pares debido a una injusticia distributiva -o una mala distribución (sic)- o cuando son afectadas por una desigualdad de estatus o reconocimiento fallido (sic), debido a la existencia de jerarquías que niegan su posición adecuada en la sociedad (Fraser, 2008). Aunque estos planteamientos se sitúan en discusiones más amplias sobre el devenir de la sociedad global trazan nuevos horizontes para las relaciones intersubjetivas en tanto permiten una aproximación analítica respecto de los mecanismos actuantes en la mayor o menor aceptación de la diversidad étnica que, por ejemplo, ha primado en Chile. En efecto, para el análisis de la coyuntura raza/género a escala global Seyla Benhabib ha señalado que:

la raza y el género son colectividades bivalentes que atraviesan el espectro de redistribución y reconocimiento. Así, ser mujer y miembro de una "raza" oprimida tendrá consecuencias tanto en la propia posición en el esquema redistributivo, como en el esquema del reconocimiento. Para eliminar la discriminación de género y el racismo se requerirá no sólo una reestructuración en el nivel de las relaciones socioeconómicas, sino también una transformación de los esquemas de reconocimiento (2006: 127). 
Tal propuesta no es antojadiza, la ausencia de reconocimiento es un constructo que feministas y teóricas/os de los estudios de género, así como diversas voces del mundo indígena, han venido consignando desde décadas para sus respectivos nichos de defensa, aunque con distintos énfasis. La vinculación entre formas de subordinación en función del género y la raza/etnia, entonces, se conecta con este tipo de inquietud pues el discurso circundante a la construcción de estas identidades conlleva un modelo que ha favorecido el mantenimiento de un status quo de relaciones asimétricas inter-étnico/raciales, entre los géneros e intra-género(s) ${ }^{23}$.

Ahora bien, ¿Cómo comprender la reiterativa y transhistórica exigibilidad de derechos por parte de los pueblos indígenas? Por una parte, retomando las ideas expuestas al inicio de esta reflexión, considero que una parte importante del discurso en torno a los derechos indígenas -donde subyacen ideas asociadas a la búsqueda de reconocimiento- apuntan a denunciar la continuada reificación que actúa como mecanismo de subordinación material y simbólico sobre los sujetos indígenas toda vez que, en la actualidad, tanto la desigualdad estructural como la circulación de doxas en torno a sus identidades persisten. Lo anterior se traduce en epítetos (e imperativos) que han cernido atributos conducentes a que se naturalicen ciertos tipos de "deber ser": "los mapuche son así", "los mapuche deben ser así", "las mujeres mapuche son así", "las mujeres mapuche deben ser así", serían algunas expresiones de este tipo que circulan como hechos incuestionables ${ }^{24}$.

Por otra parte, en un escenario menos particular, considero importante prestar atención a la creciente búsqueda de derechos que acontece a escala global; me refiero a los intentos por establecer los derechos culturales como recursos inalienables de las personas. Se trata de un hecho que llama la atención no solo porque emerge en contextos de crisis política y económica mundial sino por el sentido intrínseco que devela este tipo de discurso y planteamiento, toda vez que contiene invocaciones a:

la libertad de participar en la actividad cultural, hablar en el idioma de elección, enseñar a sus hijos a la lengua y la cultura propias, identificarse con las comunidades elegidas, descubrir toda la gama de culturas que componen la herencia mundial, conocer los 
derechos humanos, tener acceso a la educación, estar exento de ser representado sin consentimiento o de tolerar que el propio espacio cultural sea usado para publicidad, y obtener ayuda pública para salvaguardar esos derechos (Grupo de Friburgo, en Yudice, 2002: 36).

Como se observa, invariablemente, todos éstos derechos también apuntan a la consecución de distintas formas de reconocimiento, transformándose así en un síntoma social que reclama formas de justicia. Constituyen manifestaciones de lo que la percepción individual y colectiva acusa como cercamiento en las zonas de libertad. Son manifestaciones y demandas históricas de los pueblos indígenas pero que ahora emergen resignificadas desde grupos humanos en tránsito, reasentamiento y/o anfitriones de nuevas formas de alteridad en espacios territoriales inundados de crisoles socioculturales dispares. Son demandas básicas y fundamentales que solo ahora, en globalización, se hacen visibles en el cuasi obligado compartimiento de espacios locales que eclosionó ante fenómenos migratorios masivos. Un ámbito de tensiones aún irresueltas, las que derivan -entre otros- del propio locus desde donde se sitúa, define o defienden las culturas y sus fronteras ${ }^{25}$, y para las que está pendiente aportar vías de solución pues como fenómeno es susceptible de activar mecanismos reificadores de construcción/captación de alteridad, agudizando manifestaciones xenofóbicas y/o conflictos étnico/raciales.

La búsqueda del reconocimiento es un fenómeno que en el espacio discursivo converge con demandas (y defensa) para la preservación de derechos que, por ejemplo, los mapuche han perseguido desde la época colonial. Sin embargo, la histórica y limitada posibilidad de negociación favorable para este pueblo trasluce que la construcción de la nación en Chile se fundó en principios reificantes que como consecuencia desembocaron en miedo; miedo del otro, de la alteridad, no como potencial amenaza individual sino en tanto (futuro) obstáculo ${ }^{26}$. Los pueblos indígenas, entonces, pasaron a constituir una presencia cuya posición referencial en sí misma -debido a la historia fundacional de la nación- encarnaría a largo plazo un sujeto acreedor de bienes materiales y simbólicos (arrebatados). De ahí que, ante el potencial sujeto (colectivo) desestabilizador de proyectos individuales o de "clanes familiares" -que visionaron en 
la emergencia del Estado una promesa y oportunidad desde donde construir y consolidar estrategias de acumulación y dominio económico- la estrategia fue (intentar) obliterar la diferencia. Casi como un movimiento cíclico este miedo e intento de obliteración resurge cada vez que los mapuche como sujeto histórico-político revitalizan discursos en torno a la búsqueda de reconocimiento ${ }^{27}$.

A partir de lo anterior, una pregunta que queda suspendida es si este fenómeno ¿se complementa de algún modo con la creciente invocación de derechos culturales (que ya no es exclusiva de ámbitos discursivos indígenas)?

En el contexto local la comprensión de discursividades racialistas como ideología operante respecto de los pueblos indígenas desde la época de contacto con la "minoría étnica española" ${ }^{28}$ aporta elementos de análisis pero no los suficientes pues es necesario complementar acuciosamente este punto de vista de acuerdo al comportamiento resignificado de la desigualdad y el propio fenómeno ideológico que la sustenta.

Es necesario resituar el análisis y ver la creciente búsqueda de derechos individuales y colectivos como expresiones apremiantes ante el desbordado control económico actual y el apabullante modelo de sociedad que se comenzó a fraguar en la época moderna. Una expresión de este modelo se constata a escala global en la forma de crecientes oleadas migratorias que, como respuesta, genera en los espacios locales nuevas formas de miedo ante la amenaza invisible que apenas se logra vislumbrar en la estructura económica ${ }^{29}$. Asistimos, entonces, a nuevas formas de reificación de todos los sujetos que representen alteridad(es). Una demostración del intento de defensa del espacio considerado propio. Un reclamo que ahora se vuelve dialógico en tanto ahora convoca al(a) ciudadano(a) promedio.

La demanda de derechos culturales asoma, entonces, como evidencia del sujeto que percibe mecanismos reificantes sobre si, sobre su identidad y que resiente, en el modo asimétrico en que se inserta en sociedad y relaciones circundantes, su falta de reconocimiento ${ }^{30}$. La oleada pro-derechos culturales da cuenta de una demanda que, aunque soterrada, está presente al revisar la historia de las mujeres y de los pueblos indígenas pues, tal como fuera señalado, el reconocimiento es una demanda que feministas y teóricas/os de los estudios de género, así como diversas voces del mundo indígena, han 
venido consignando desde décadas para sus respectivos nichos de defensa.

Esta cuestión, sin embargo, no logra resolver algunos problemas y es que si se intentara apostar por un discurso de la igualdad suprimiendo la existencia de marcas que signan la diferencia (del tipo que sea), ¿cómo se restituye socialmente a los hombres y mujeres que han sido afectados por tales marcas desde un discurso de la igualdad?, ¿qué procesos deben ocurrir en forma paralela para que reificaciones sobre niñas y mujeres indígenas no continúen siendo obliteradas? ${ }^{31}$. Lo anterior constituye un campo de inquietudes que exceden el alcance de este texto pues requiere de una reflexión continua y colectiva que concierne a los pueblos indígenas, a las mujeres y hombres de esos pueblos, pero también a la sociedad en su conjunto ${ }^{32}$. Mientras tanto para otros efectos, los más prácticos, el reconocimiento continúa pendiendo en incertidumbres y sujeto a diversas manipulaciones e intereses políticos y económicos que generalmente resultan desconocidos (aunque no en sus impactos) para quienes cotidianamente son reificados(as).

\section{Notas}

1. Agradezco los comentarios de Ingrid Wehr y Marcela Sandoval a una versión preliminar de este ensayo.

2. En efecto, se ha señalado que el discurso etnificador gravitó en la constitución de un nuevo sujeto histórico colectivo, en tanto actuó "como una categoría que se impuso por sobre las poblaciones prehispánicas, homogeneizándolas, y borrando paulatinamente diferencias preexistentes. Se produjo así (...) una inversión clasificatoria, a través de la cual, lo "indio" terminó por transformarse en el término genérico de la clase y los nombres quedaron como subclase de la nueva categoría" (Gallardo et al., 2002: 171).

3. Aunque la noción de discurso es polisémica y, en tal sentido, en este texto es prácticamente inevitable recurrir a las diversas variaciones de sentido que entraña el concepto, me baso fundamentalmente en Joan Scott quien (en referencia a Michel Foucault) señala que los discursos son campos de conflicto y poder desde donde se elaboran y legitiman significados. De tal modo, el discurso en sí mismo "no es un lenguaje ni un texto, sino una estructura histórica, social e institucionalmente específica de enunciados, términos, categorías y creencias" (Scott, 1992: 87).

4. Sobre estos temas véase Potthast, quien señala como en Paraguay y Cuba no fueron negados los orígenes indígenas ni afrodescendiente en las identidades nacionales (Potthast, 2009). Sobre la exclusión de los mapuches en el espacio simbólico y material de la formación nacional Pinto (2003), Subercaseaux (2005), Richards 
(2010), Bello (2012), entre otros.

5. Instituciones educativas y el propio impulso del Estado docente.

6. Tales como los enclaves militares y misioneros. Para Jorge Pinto esta estrategia se debió a que hasta mediados del siglo XIX era extremadamente complejo reemplazar la burocracia colonial (sic) puesto que hasta 1852 "no existía en el territorio indígena una provincia y sus respectivas subdivisiones administrativas. Las autoridades conocían bien estas dificultades, por eso no introdujeron mayores modificaciones e insistieron en los misioneros y en los parlamentos para relacionarse con los mapuche" (Pinto, 2003: 129).

7. Señalo este concepto para referirme a viajeros exploradores que recorrieron América Latina durante el siglo XIX.

8. Expresión en mapudungun que refiere al territorio mapuche.

9. Al respecto, el trabajo de Jorge Pinto es particularmente importante pues coloca en perspectiva diacrónica este tema. En específico, señala: "Si los hombres del siglo XVI y del siglo XVII habían dado muestras de incomprensión e intolerancia, los del siglo XIX fueron todavía mucho más lejos. Su etnocentrismo y postura, a veces abiertamente genocidas, alcanzaron niveles hasta entonces desconocidos" (2003: 151).

10. Me baso en Guillaume Boccara, quien se refiere al fenómeno de la guerra como dispositivo de construcción/captación de alteridad. De acuerdo a ello, la ampliación de esta idea al ámbito de conflictos (genéricos) se propone toda vez que este autor consigna que: "el enemigo es con quien uno se enfrenta, es también de quien nos servimos para definir nuestra identidad. En otros términos, el modo mediante el cual determinada sociedad trata al enemigo, así como el uso y material simbólico que se hace de él, nos ilustra sobre la manera como se concibe la alteridad" (Boccara, 2007: 186).

11. Y añade: "Igualmente, la gente puede proclamar una identidad racial que represente para ellos aspectos esenciales de sus personas; de hecho, en los EEUU, la identidad racial está tan politizada que nadie escapa por completo a esa definición" (Wade, 2000: 21).

12. Raza y etnicidad entonces serían una construcción social para la diferencia y la igualdad y/o delimitadora de las diferencias fenotípicas en el caso de la primera, y culturales en la segunda. Opto por usar esta definición simplificada y abreviada, y que puede considerarse un símil del planteamiento de Peter Wade, toda vez que éste apunta a que "las identificaciones raciales y étnicas se superponen tanto analítica como prácticamente" (Wade, 2000: 29).

13. Sobre las variaciones que ha ido adquiriendo el discurso racista véase, por ejemplo, Stolcke (2000). Aunque la revisión que hace la autora se enfoca en Europa resulta interesante su modelo de análisis, en tanto insta a indagar los significados que adquiere el concepto raza en cada contexto epocal, a fin de evitar riesgos que conlleva una perspectiva en exceso "presentista" en el análisis histórico.

14. En tal sentido se ha señalado que algunas estrategias adoptadas en forma reciente han sido "disminuir fuertemente el papel de los movimientos indígenas en el seno de la CONADI por la vía de profesionalizar la institución y reducir el poder de decisión de los "consejeros indígenas". Por otro lado, y frente al sector radical, la tónica ha sido recurrir a la represión y a los tribunales de justicia. Debido a ello, un número muy alto de dirigentes mapuches, especialmente de la Coordinadora 
Arauco-Malleco, han sido detenidos y procesados, utilizando, en muchos casos, la legislación anti-terrorista heredada de la dictadura militar. Se ha producido también una suerte de militarización de algunas áreas en conflictos, con retenes policiales ubicados en las entradas de fundos forestales, operativos de incautación de madera, arrestos en comunidades, e inclusive la muerte de tres jóvenes mapuches" (Vergara et al., en prensa, 2013). Sobre el rol del Estado amparado en el contexto discursivo del multiculturalismo neoliberal véase Richards (2010).

15. Con este uso semántico me refiero al concepto de performatividad que tal como lo acuñara Judith Butler "no es pues un 'acto' singular, porque siempre es la reiteración de una norma o un conjunto de normas y, en la medida en que adquiera la condición de acto en el presente, oculta o disimula las convenciones de las que es una repetición" (Butler, 2005: 34).

16. En la escritura postcolonial de Aime Cesaire (1993) la ideología colonialista está impregnada de contenidos etnocéntricos cuya huella quedó plasmada en textos que se invocan como historia oficial. Pero hay más. Un tema que surge con especial sensibilidad para Cesaire es su malestar con la producción intelectual Europea y de Occidente en tanto reproductora o transmisora de un sistema de dominación y castradora de todo lo que escape al referente que se instaura como EL modelo cultural por excelencia: blanco, civilizado, entre otros.

17. Al respecto véase Pinto (2003), Bengoa (2000), Subercaseaux (2005), entre otros. 18. El autor ejemplifica así: "en su propia actividad social, en lo que hacen, las personas actúan como si el dinero, en su realidad material, fuera la encarnación inmediata de la riqueza en tanto tal" (Zizek, 2003: 59). El ejemplo es clave para entender cómo interpreta la reificación desde una aproximación centrada en el psicoanálisis, del cual toma el concepto de fetiche.

19. El autor cita la Crítica de la razón cínica de Meter Sloderdijk (Zizek, 2003: 57)

20. En su revisión de este concepto Honneth señala que reificación "quiere decir aquí una costumbre de pensamiento, una perspectiva que se fosilizó y se convirtió en hábito, a partir de cuya adopción el sujeto pierde la capacidad de implicarse con interés, del mismo modo que su entorno pierde el carácter de accesibilidad cualitativa" (Honneth 2007: 51).

21. Respecto de este tema véase, por ejemplo, Boccara quien identifica "una historiografía nacionalista, etnocéntrica y a veces abiertamente racista" (2007: 25), cuando se trata de evaluar la mayor (o menor) legitimidad de (por ejemplo) las reivindicaciones territoriales mapuche.

22. La reificación representa un "quebrantamiento de una condición práctica a la que se encuentra sujeta necesariamente la reproducción de nuestro mundo de la vida social" (Honneth, 2007: 106). A juicio del autor esto abre la discusión sobre los grados de implicación que podemos adoptar en nuestras interacciones sociales. Una condición ideal, opuesta a la reificación, entonces, apuntaría a una necesaria identificación previa, un dejar existir en nosotros a nuestros(as) interlocutores para incluirme existencialmente en su mundo.

23. Un mecanismo que tal vez también opera en forma intraétnica e intragénero al interior de la(s) etnia(s).

24. Se trata de atributos que activan dicotomías tales como "indios buenos" v/s "indios malos". Una revisión actualizada de este modelo y la noción de "indio permitido" la proporciona Patricia Richards (2010). 
25. Me refiero a debates actuales sobre la inconmensurabilidad de las culturas, a partir de lo cual se ha propuesto que “(...) la articulación de un universalismo ético e ilustrado de viso pluralista a escala mundial surge como una posibilidad y una necesidad.

1. La interpretación de las culturas como totalidades herméticas, selladas e internamente autocoherentes es insostenible y refleja una sociología reduccionista del conocimiento.

2. Esta visión de las culturas como totalidades autocoherentes también es refutada por los argumentos filosóficos relativos a la imposibilidad de la inconmensurabilidad y la intraducibilidad radicales.

3. Si toda comprensión es interpretación del (los) otro(s) también debe cobrar sentido para nosotros desde el lugar que nos posicionamos en la actualidad, entonces las fronteras de la comunidad de conversación se extienden tan lejos como nuestros intentos permanentes de comprender, interpretar y comunicarnos con el (los) otro(s)" (Benhabib, 2006: 77).

26. Patricia Richards (2010) también menciona este tipo de percepción a partir de una mirada actual centrada en las relaciones intersubjetivas, entre colonos y elites locales con descendientes mapuche, en la IX región.

27. La ideas del "resurgimiento mapuche" es tomada de Boccara, quien aborda las llamadas formas de resistencia mapuche en el tránsito histórico de la época colonial y que creo son previsibles de proyectar en el periodo republicano (Boccara, 2007). En un análisis más próximo a la actualidad cabe destacar que Juan Carlos Skewes ha señalado que "La prensa y los sectores conservadores ven la irrupción de este movimiento como una nueva "guerra de Arauco", la "cuestión mapuche" como había sido concebida en el pasado pasa a ser el "conflicto mapuche" que divide a la propia sociedad chilena entre quienes separan a los mapuche "buenos" de los "malos" y aquellos que ven realizado en los pueblos originarios el sueño ecológico" (Skewes en Aylwin, 2004: 393)

28. Marimán et al (2006) aluden este tropo.

29. Verena Stolcke plantea que en Europa se observa un desplazamiento del racismo en la forma de "fundamentalismo cultural" (sic) para justificar formas de exclusión. Señala: "Planteamientos racistas más o menos aislados fueron desplazados por una evocación ubicua de la cultura, es decir, de la diferencia cultural, y una argumentación que ahora exalta la identidad e integridad nacionales y la paz social que se suponen amenazadas por esos inmigrantes de hábitos culturales diferentes y que pretenden apropiarse de nuestra buena vida" (2000: 52).

30. En tal sentido, se ha señalado que: "Nuestra identidad está parcialmente modelada por el reconocimiento o por su ausencia, con frecuencia por el reconocimiento distorsionado de los otros, por lo que una persona o un grupo de personas puede sufrir un daño real, una distorsión real, si la gente o la sociedad que está a su alrededor les devuelve un reflejo de sí mismos limitante, degradante o despectivo" (Taylor, 1992 en Benhabib: 96).

31. En particular, me refiero a condiciones objetivas que han afectado, por ejemplo, a mujeres mapuche dada la existencia de una triple discriminación y debido a su frecuente invisibilidad analítica en diversos estudios, encuestas, entre otros. Véase, por ejemplo, González Caniulef (2004).

32. Con todo, cada vez cobra más fuerza recordar que "cuando la igualdad y di- 
ferencia se plantean dicotómicamente, estructuran una elección imposible. Si una opta por la igualdad, está forzada a aceptar que la noción de diferencia es su antítesis. Si una opta por la diferencia, admite que la igualdad es inalcanzable" (Scott, 1992: 99). Pese a que este dilema filosófico fue planteado en la teoría de género hace un par de décadas aún no logra convocar acuerdos.

\section{Bibliografía}

Bello, Alvaro. “Hegemonía, historia y pueblos indígenas en la formación del Estado-nación chileno". Zotero. Mayo, 2012. Consultado en: http://www. zotero.org/spartakku/items/itemKey/73FNAXMS

Bengoa, José. Historia del pueblo mapuche. Siglos XIX y XX. 1985. Santiago: Lom ediciones, 2000.

Benhabib, Seyla. Las reivindicaciones de la cultura. Igualdad y diversidad en la era global. Buenos Aires: Katz, 2006.

Boccara, Guillaume. Los vencedores. Historia del pueblo mapuche en la época colonial. San Pedro de Atacama-Chile: IIAM, 2007.

Butler, Judith. Deshacer el género. Barcelona: Ediciones Paidós, 2006.

-----.- Cuerpos que Importan: Sobre los límites materiales y discursivos del sexo. Buenos Aires: Paidós, 2005.

Casanova, Holdenis.: Entre la Ideología y la Realidad: La Inclusión de los Mapuche en la Nación Chilena (1810-1830). Revista de Historia Indígena. (4), 1999: 9-48.

Césaire, Aimé. "Discurso sobre el Colonialismo". En: Zea, Leopoldo, comp. Fuentes de la Cultura Latinoamericana. Vol. II. México: Fondo de Cultura Económica, 1993: 306-324.

Fraser, Nancy. Escalas de justicia. Barcelona: Herder Editorial, 2008.

Gallardo, Viviana, et al. "Indios y Rotos: El surgimiento de nuevos sujetos en los procesos de construcción identitaria latinoamericana". Revista Universum. (17), 2002: 171- 177.

Gallardo, Viviana: Héroes Indómitos, Bárbaros y Ciudadanos Chilenos: El Discurso Sobre el Indio en la Construcción de la Identidad Nacional. Revista de Historia Indígena. (5) 2001: 119-134.

González Caniulef, Elsa: "La discriminación en Chile: el caso de las mujeres mapuche". En Ed. Aylwin, José. Derechos humanos y pueblos indígenas. Tendencias internacionales y contexto chileno. Temuco-Chile: Instituto de Estudios Indígenas, 315-326, 2004.

Gross, Elizabeth. “Derrida, Irigaray and Deconstruction”. En: Scott, Joan. “Igualdad versus diferencia: los usos de la teoría postestructuralista". Debate Feminista. (5), 1992: 85-104.

Grupo de Friburgo. "Project concerning a declaration of cultural rights". En Yudice, George. El recurso de la cultura. Usos de la cultura en la era global. Barcelona: Gedisa, 2008.

Honneth, Axel. Reificación: un estudio en la teoría del reconocimiento. Buenos Aires: Katz, 2007.

Marimán Pablo, et al. ¡...ESCUCHA winka...! Cuatro ensayos de Historia Nacional Ma- 
puche y un epílogo sobre el futuro. Santiago: Lom ediciones, 2006.

Nash, Mary. "Representaciones culturales y discurso de género, raza y clase en la construcción de la sociedad europea contemporánea". s.l.n.a. Consultado en http://www.desafio.ufba.br/gt4-012.html

Pinto, Jorge. La formación del Estado y la nación, y el pueblo mapuche. De la inclusión a la exclusión. Santiago Ediciones de la Dirección de Bibliotecas, Archivos y Museos, 2003.

Potthast, Bárbara. "Female Soldiers and National Heroes in Latin America" En Ed. Dülffer, Jost and Frank, Robert. Peace, War and Gender from Antiquity to the Present. Cross-Cultural Perspectives. Essen: Klartext Verlag, 2009: 181-203.

Richards, Patricia. De indios y terroristas. Como el estado y las elites locales construyen el sujeto Mapuche en Chile. Traducción de su “Of Indians and Terrorists: How the State and Local Elites Construct the Mapuche in Neoliberal Multicultural Chile". Journal of Latin American Studies (42), 2010: 59-90.

Rubin, Gayle. "El tráfico de las mujeres: notas sobre la "economía política" del sexo". Revista Nueva Antropología. (30) 1986: 95-145.

Scott, Joan. "Igualdad versus diferencia: los usos de la teoría postestructuralista". Debate Feminista. (5): 1992: 85-104.

Skewes, Juan Carlos. Creando desorden: Orígenes, el estado y la sociedad mapuche en Chile. En Ed. Aylwin, José. Derechos humanos y pueblos indígenas. Tendencias internacionales y contexto chileno. Temuco: Instituto de Estudios Indígenas, 2004: 389-405.

Stolcke, Verena. "Sexo es a género lo que raza es a etnicidad". Márgenes, (9), 1992: 65-90.

Stolcke, Verena. “ ¿Es el sexo para el género lo que la raza para la etnicidad... y la naturaleza para la sociedad?". Política y Cultura, (14), 2000: 25-60.

Subercaseaux, Bernardo. "Pensamiento operante y construcción de nación durante el siglo XIX". En Loyola Manuel y Grez Sergio, comp. Los proyectos nacionales en el pensamiento político y social chileno del siglo XIX. Santiago: Lom ediciones, 2005.

Vergara, Jorge et al. Politica estatal, conflicto y cambio cultural. Estudios sobre pueblos indígenas en Chile. En prensa, 2013.

Wade, Peter. Raza y Etnicidad en Latinoamerica. Quito - Ecuador: Ediciones Abya Yala, 2000

Zizek, Slavoj. El sublime objeto de la ideología. Buenos Aires: Siglo veintiuno editores, 2003. 